American Journal of Pharmaceutical Education 2020; 84 (1) Article 847714.

\title{
COMMENTARY
}

\section{Curricular Hoarding}

\author{
Frank Romanelli, PharmD, MPH \\ University of Kentucky College of Pharmacy, Lexington, Kentucky \\ Executive Associate Editor, American Journal of Pharmaceutical Education, Arlington, Virginia
}

Submitted June 5, 2019; accepted July 8, 2019; published January 2020.

\begin{abstract}
As practice evolves and scientific advancements are achieved the natural inclination for educators and administrators is to add new content to existing curricula. Often pre-existing curricula that may be outdated or no longer relevant may go un-checked leading to excessive coursework and program completion times. Faculty may also have emotional or other attachments to certain topics or content and that may serve as an additional or independent barrier to removing extraneous material. To avoid and curtail curricular hoarding of material it may be prudent to periodically engage in reviews of material assessing them for not only adherence to accreditation standards but also in terms of their ongoing appropriateness and relevance to contemporary pharmacy practice. These exercises may be especially important today given the rate of information creation and dissemination in the modern digital age.
\end{abstract}

Keywords: curriculum, pharmacy education, curriculum development

The American Psychiatric Association characterizes hoarders as individuals who excessively save items that others would likely find worthless. ${ }^{1}$ Hoarders persistently find it difficult to part with possessions, thus leading to extreme clutter that can disrupt living and working spaces. Hoarding is not the same as collecting. Collectors amass items with purpose and intention, often organizing and displaying their possessions. People with hoarding disorder accrue random items, storing them haphazardly. Hoarders are particularly drawn to items they feel may be needed in the future or that have some sentimental value. A final element of the disorder is that hoarders often feel safer when they are surrounded by the items they have accumulated. Faculty and administrators often engage in circular hoarding where topics, modules, or entire courses are "hoarded" into degree programs. The challenges associated with curricular hoarding are compounded by increasing accreditation requirements as well as other internal and external factors.

Rational expansions in pharmacy training have occurred consistently since the 1800 s, extending from early pharmacy apprenticeship models to current day Doctor of Pharmacy (PharmD) degree programs. Apprenticeship served as the foundation for pharmacy education with modern day experiential education remaining a vestige of

Corresponding Author: Frank Romanelli, University of Kentucky College of Pharmacy, 789 South Limestone Rd., Lexington, KY, 40536. Tel: 859-257-4778. Email:

froma2@uky.edu this system of training. ${ }^{2}$ Various degrees have punctuated the history of pharmacy education including the Graduate in Pharmacy $(\mathrm{PhG})$ and Pharmaceutical Chemist diploma programs, which were two and three years in length, respectively. The four-year baccalaureate degree emerged in the 1940s and eventually expanded to five years in length before the PharmD degree was embraced as the entry-level credential for pharmacy practice in 2000 . The evolution of training and education programs has to some degree mirrored practice changes, transitioning from a product to a patient-centered focus. In 2000, the Accreditation Council for Pharmacy Education (ACPE) ceased to recognize baccalaureate programs and began accrediting only the PharmD degree. Since that time, multiple iterations of the Standards required for PharmD degree programs have been published by ACPE, with the most recent being in 2016. ${ }^{3}$ The 2016 version of the Standards were also accompanied by a guidance document. Corollary to the Standards, multiple versions of the Center for the Advancement of Pharmacy Education (CAPE) Educational Outcomes have been published, the most recent of which was in 2013. ${ }^{4}$ In 2017, the American Association of Colleges of Pharmacy (AACP) Academic Affairs committee published a document outlining core entrustable professional activities (EPAs) for new pharmacy graduates. ${ }^{5}$

Commensurate with evolutions and advancements in pharmacy practice, as well as the dawning of the digital information age, educators are under increased pressure to modify, modernize, and continually update the 


\section{American Journal of Pharmaceutical Education 2020; 84 (1) Article 847714.}

PharmD curricula. There is certainly no deficit in instructional documents between the Standards, Standards Guidance booklet, CAPE outcomes, and EPAs. The digital age coupled with technologic innovations has revolutionized our ability to develop, store, and transmit an unimaginable amount of information. ${ }^{6}$ The burden of "teaching" this information is inherent on the Academy and often may produce significant expectations of colleges and schools of pharmacy. When confronted with the burgeoning expanses of information, faculty instinct will most often dictate the need to add, augment, and complement.

As reflected with each iteration of ACPE Standards, there is "new" content to be taught as well as assessed. Depending on when an individual completed their pharmacy coursework, much of the modern-day curriculum may not ever have existed. The continual emergence of novel diseases and disease states continues to result in modifications to therapeutic instruction. Helicobacter pylori was only first recognized in 1982, and antibiotic treatment for it was not recommended until 1994. ${ }^{7}$ The first cases of Human Immunodeficiency Virus (HIV) were reported in the United States in 1981, but the first antiretroviral agent (zidovudine) did not become available until $1987 .{ }^{8}$ Since that time, some 30 different agents and combinations of agents have become available. With the events surrounding 9/11, the pharmacist's role in disaster preparedness and bioterrorism became of greater importance beginning in 2001. Most recently, curricular emphasis on understanding, managing, and treating substance abuse disorders has emerged as a priority within pharmacy and most health care professions.

Curricular modifications have not been limited to the discovery and emergence of new disease states. In response to modifications in pharmacy practice laws regarding immunizations, the mid-1990s saw instruction regarding vaccination delivery becoming a critical component of curricula. Many colleges and schools adopted and still utilize the American Pharmacists Association Pharmacy-Based Immunization Delivery Program. Congruent with the shift towards patient-centric practice, physical assessment became an element of most PharmD programs as well as ACPE Standards. Increased emphasis on prevention and the health of large populations of patients has brought public health instruction as well as evidenced-based medicine into pharmacy education. Colleges and schools have also modernized curricula by adding instruction related to a variety of topics, including the care of lesbian, gay, bisexual, and transgender (LGBT) patients and informatics. Another emerging trend is the inclusion of board examination preparatory courses and coursework within the formal PharmD curriculum.

With the required instruction of new and more voluminous topics comes the corollary responsibility of assessing that learning. Colleges and schools have markedly improved both the volume and quality of assessments. Objective standardized clinical examinations (OSCEs) have become commonplace as a means of more authentic testing. ${ }^{9}$ Objective standardized clinical examinations are both resource and time intensive when compared to traditional paper and pencil testing. Students are now also required to sit for the Pharmacy Curriculum Outcomes Assessment (PCOA). ${ }^{3}$ Other modifications to curricula have included greater emphasis on exposure to patients and patient care activities both early and often within PharmD curricula. This reflects requirements surrounding early and intermediate pharmacy practice experiences. Students are also expected to be engaged in co-curricular activities.

Curricular drift is a well-known phenomenon within pharmacy education, but curricular hoarding is another phenomenon warranting attention. ${ }^{10}$ At my institution, one goal of a recent PharmD program curricular reform was to reduce required credit hours and decompress the curriculum. We were only successful in eliminating eight credit hours of coursework. Both external and internal pressures remain on faculty members to add content to existing curricula, but discussions surrounding elements that could or should be deleted are not as common. The deletion of curricular elements, especially ones that may have for years served as foundations or mainstays of a curriculum may be difficult to accomplish. Like hoarders, faculty members and administrators may find solace or security in the compulsory instruction of certain content. Emotional attachments to certain courses or content may make it difficult to part with these "curricular possessions." Faculty members and administrators must be vigilant in avoiding curricular hoarding. The amassing of coursework that may be antiquated or otherwise unnecessary only leads to the bloating of credit hours within curricula. It may in turn lead to course crowding and reduced "think time" for students, and create unnecessarily long days, full schedules, student frustration, and physical space limitations.

The Academy should engage in serious discussions centered on content that might be eliminated from curricula to "make room" for contemporary items. An obvious solution might be to map content to Standards 2016 and engage in an elimination exercise, but this is not always as simple as it seems. In referencing specific topics or curricular elements, the Standards often lack direction related to the exact depth and breadth with which certain 


\section{American Journal of Pharmaceutical Education 2020; 84 (1) Article 847714.}

topics may need to be instructed. This may lead to an over reliance upon simple discretion when making decisions and may serve as an unchecked reason to simply accede to inclusion. Faculty members, like hoarders, may often have sentimental or nostalgic attachments to certain content or courses. Familiarity, whether associated with our homes, our friends, our cars, or our local grocery store, breeds feelings of safety. While older content that has been instructed over and over in a time-tested manner might make us feel safer, its hard to grow without stepping into the outer limits of our curricular comfort zones.

\section{REFERENCES}

1. American Psychiatric Association. Diagnostic and Statistical Manual of Mental Disorders, Fifth edition. 2013. American Psychiatric Publishing.

2. Fink JL. Pharmacy: A brief history of the profession. Student Doctor Network. https://www.studentdoctor.net/2012/01/pharmacya-brief-history-of-the-profession/. Updated January 11, 2012.

Accessed June 4, 2019.
3. Accreditation Council for Pharmacy Education. Accreditation standards and key elements for the professional program in pharmacy leading to the doctor of pharmacy degree. https://www.acpe-accredit.org/ pdf/Standards2016FINAL.pdf. Accessed June 4, 2019.

4. Medina MS, Plaza CM, Stowe CD, et al. Center for the Advancement of Pharmacy Education (CAPE) Educational Outcomes 2013. Am J Pharm Educ. 2013;77(8);Article 162.

5. Pettinger AL, Chapman SA, Frail CK, et al. Entrustable professional activities for pharmacy practice. Am J Pharm Educ. 2016;(80)4:Article 57.

6. Hilbert M, Lopez P. The worlds technological capacity to store, communicate, and compute information. Science 2011;332:60-65.

7. Warren JR, Marshall B. Unidentified curved bacilli in on gastric epithelium in in active chronic gastritis. Lancet 1983;321:1273-1275. 8. Gottlieb MS, Schanker HM, Saxon A, et al. Pneumocystis Pneumonia --- Los Angeles. MMWR 1981;30:1-3.

9. Brannick MT, Erol-Korkmaz HT, Prewett M. A systematic review of the reliability of objective standardized clinical examination scores. Med Educ 2011;45(12):1181-1189.

10. Robins LS, White CB, Fantone JC. The difficulty of sustaining curricular reforms: a study of "drift" at one school. Acad Med. 2000;75(8):801-805. 